\title{
Comparative Study on Summer Tourism Development in Xining City
}

\author{
LI Chen-Yang ${ }^{1, a}$, CHEN Jin-Lin ${ }^{2}$ b* $^{*}$ \\ ${ }^{1}$ Department of tourism and business administration, Qinghai University, Xining, Qinghai, China \\ ${ }^{2}$ Department of tourism and business administration, Qinghai University, Xining, Qinghai, China
}

\begin{abstract}
In recent years, people's demand for cool climate environment has promoted the vigorous development of summer tourism activities. Xining is the largest city on the Qinghai-Tibet Plateau, and has great advantages in developing summer tourism. In this paper, several popular summer tourism cities in China in 2019 are selected. By comparing the development conditions of summer tourism between Xining and these cities quantitatively and qualitatively, the advantages and disadvantages of developing summer tourism in Xining are analyzed, and targeted suggestions are put forward for the development of summer tourism.
\end{abstract}

\section{Introduction}

With the aggravation of global warming and urban heat island effect, the number of days of extreme high temperature in summer is increasing. The report of Intergovernmental Panel on Climate Change (IPCC) points out that the number of days of extreme high temperature and heat wave is very likely (reliability $>90 \%$ ) to keep rising[1]. Based on the physiological needs of tourists, summer tourism, as a kind of tourism activity with cool and comfortable summer climate as its main attraction and motivation, will be further popularized as a mode of focusing on building tourist destinations and developing tourism in the era of mass tourism.

The research dimensions of summer tourism in China are very diverse. After the concepts of "summer tourism" and "summer industry" were clearly defined in the first summer tourism economic forum in China in 2007, Jin Yingruo (2010) proposed that summer tourism should take the road of characteristics and ecology[2]. Chen Hui et al. (2015) pointed out that there are five types of regions suitable for developing summer tourism in China, including northeast mountain plain type, northwest mountain plateau type, southwest plateau type, central and eastern mountain type, and Bohai Rim low mountains and hills type[3]. Yang Jun et al. (2016) empirically studied and discussed the spatial suitability distribution[4] of summer tourism base construction. Lu Wenli (2019) thinks that summer tourism needs not only cool climate, but also "poetry and distance", and attaches importance to cultural enjoyment[5]. Chen Han (2019) emphasized the development of "summer economy", not only relying on natural tourism resources, but also working hard on the "supply side"[6]. Summer tourism has increasingly become a hot issue in the study of tourism destination development.

In 2019, Changchun, Guiyang, Liupanshui, Kunming,
Xining, Aershan, Fusong County of Baishan, Dunhua, Xixiu District of Anshun and Pu 'an County of Southwest Guizhou Province were rated as "Top Ten Cities for Summer Tourism"[7]. With the unique plateau climate without intense heat in summer, Xining has been actively creating the business card of "cool city" in the world since 2012, and has been honored as "Summer Capital". However, in terms of tourism income, the annual income of Xining tourism can only reach $1 / 9$ of that of other popular summer tourist cities. Tourism is the key pillar industry in Xining. In order to ensure the full play of economic benefits, Xining needs to explore the development road of summer tourism which is suitable for its own conditions. By comparing the relevant data between Xining and several popular summer tourism cities, this paper analyzes Xining's own characteristics, advantages and shortcomings, and puts forward a series of suggestions for improvement and development, so as to realize the precise positioning and rapid development of summer tourism in Xining.

\section{Evaluation system and calculation method}

\section{1 evaluation system}

In this paper, four climatic factors are selected, which constitute two evaluation indexes: temperature and humidity index (THI) and wind efficiency index (K), and constitute the evaluation system of summer climate $(\mathrm{C} 1)$. Select the number of $4 \mathrm{~A}+$ scenic spots, the number of hotels above 3 stars, the number of tourists and income, and construct the evaluation system of industrial conditions (C2); Four factors, including forest coverage rate, air quality, number of cultural places and number of cultural and gourmet blocks, are selected to form two

\footnotetext{
a E-mail: 1223345785@qq.com

b, *Corresponding E-mail: cj13716@163.com. TEL:13897410065
} 
evaluation indexes, namely, healthy environment and cultural environment, and an external environment (C3) evaluation system is constructed. This paper compares the summer climate (C1), industrial conditions (C2) and external environment (C3) between Xining City and other summer tourism cities horizontally, analyzes the strengths and excavates shortcomings, and puts forward practical development suggestions.

\section{2 data sources}

In 2019, Guiyang, Kunming and Changchun, which are located in northwest, southwest and northeast of China, are selected as the top ten summer tourism cities in China, and compared with Xining. After the comparison objects are determined, the comparison data are collected from the ecological environment department, forestry and grassland bureau, the reports of the two sessions of the government, Ctrip and other platforms.

Meteorological data comes from routine ground meteorological observation data of Xining, Guiyang, Kunming and Changchun in China Meteorological Science Data Sharing Service Network in 2019. The meteorological elements selected from the data of each station include temperature $(\mathrm{t})$, relative humidity (f), wind speed (v) and sunshine hours (s). As July is the peak period of summer tourism, July is selected as the main research period.

\section{3 calculation method}

Select air temperature (t), relative humidity (f), wind speed (v) and sunshine hours (s) to form the bottom layer of elements; Two evaluation indexes, temperature and humidity index (THI) and wind efficiency index $(\mathrm{k})$, are selected to form the middle index layer. Temperaturehumidity index (THI), proposed by Oliver.J.E on the basis of naked experiment, refers to the temperature after humidity revision, which reflects the heat exchange between human body and surrounding environment through the combination of temperature and humidity, and can effectively show the comprehensive influence of temperature and humidity on human body's heat perception. Wind efficiency index $(\mathrm{k})$ evolved from wind chill index $\mathrm{WCI}=(33-\mathrm{t})(9.0+10.9 \quad \sqrt{ } \mathrm{v}-\mathrm{v})$, and also considered the heat absorption effect of solar radiation on human body, which reflected the heat exchange between body surface and environment, with positive value for heat absorption and negative value for heat dissipation. The formula is as follows[8]:

$$
\begin{aligned}
& T H I=(1.8 \mathrm{t}+32)-0.55(1-\mathrm{f})(1.8 \mathrm{t}-26) \\
& K=-(10 \sqrt{\mathrm{v}}+10.45-\mathrm{v})(33-\mathrm{t})+8.55 s
\end{aligned}
$$

In which $\mathrm{t}$ is the temperature in celsius $\left({ }^{\circ} \mathrm{C}\right)$; $\mathrm{f}$ is relative humidity $(\%) ; \mathrm{v}$ is wind speed $(\mathrm{m} / \mathrm{s}) ; \mathrm{s}$ is sunshine hours $(\mathrm{h} / \mathrm{d})$.

\section{Comparison of development factors of summer tourism}

\subsection{Climate comparison}

The following are the meteorological data of Xining, Guiyang, Changchun and Kunming in the summer of July 2019:

Table 3-1 Meteorological data of four summer cities in 2019

\begin{tabular}{ccccc}
\hline region & $\begin{array}{c}\text { Average } \\
\text { temperature } \\
\left({ }^{\circ} \mathrm{C}\right)\end{array}$ & $\begin{array}{c}\text { Relative } \\
\text { humidity } \\
(\%)\end{array}$ & $\begin{array}{c}\text { Sunshine } \\
\text { hours }(\mathrm{h} / \mathrm{d})\end{array}$ & $\begin{array}{c}\text { Average } \\
\text { wind } \\
\text { speed } \\
(\mathrm{m} / \mathrm{s})\end{array}$ \\
\hline Xining & 16.5 & 65.1 & 6.59 & 2.6 \\
$\begin{array}{c}\text { Guiyang } \\
\text { Changch } \\
\text { un }\end{array}$ & 22.7 & 83.9 & 3.82 & 2.1 \\
Kunming & 18.8 & 76.5 & 11.18 & 2.2 \\
\hline Data source: China Meteorological Data Sharing Service Network
\end{tabular}

According to formulas (1) and (2), the temperature and humidity index and wind efficiency index of the four major summer tourist cities in July 2019 are obtained. The data results are as follows:

Table 3-2 Temperature and humidity index and wind efficiency index of four summer cities in 2019

\begin{tabular}{ccccc}
\hline region & Xining & Guiyang & Changchun & Kunming \\
\hline $\begin{array}{c}\text { Temperature } \\
\text { and humidity } \\
\text { index (THI) } \\
\quad \text { Wind } \\
\begin{array}{c}\text { efficiency } \\
\text { index (k) }\end{array}\end{array}$ & -339.16 & 71.75 & 73.92 & 65.05 \\
\hline
\end{tabular}

On the basis of quantitative analysis, four summer tourism cities are qualitatively analyzed. Divide the scores of the two indexes into five levels, and assign values to the five levels from "most suitable" to "extremely unsuitable" with scores of 9, 7, 5, 3 and 1 respectively, as shown in the table:

Table 3-3 Classification Standard and Assignment of

\begin{tabular}{|c|c|c|c|c|c|}
\hline \multicolumn{2}{|c|}{$\begin{array}{l}\text { temperature-humidity index } \\
\text { (THI) }\end{array}$} & \multicolumn{2}{|c|}{ Wind efficiency index } & \multicolumn{2}{|c|}{$\begin{array}{l}\text { Symbol and } \\
\text { assignment }\end{array}$} \\
\hline $\begin{array}{l}\text { Value } \\
\text { range }\end{array}$ & $\begin{array}{c}\text { People's } \\
\text { sensory status }\end{array}$ & $\begin{array}{l}\text { Value } \\
\text { range }\end{array}$ & $\begin{array}{l}\text { People's } \\
\text { sensory } \\
\text { status }\end{array}$ & grade & $\begin{array}{l}\text { evalu } \\
\text { ation }\end{array}$ \\
\hline$<40$ & $\begin{array}{l}\text { It's extremely } \\
\text { cold and } \\
\text { uncomfortable }\end{array}$ & $\leq-1000$ & $\begin{array}{l}\text { Very cold } \\
\text { wind }\end{array}$ & $\mathrm{e}$ & 1 \\
\hline $40-45$ & $\begin{array}{c}\text { Cold, } \\
\text { uncomfortable }\end{array}$ & $\begin{array}{l}-800 \sim- \\
1000\end{array}$ & cold air & d & 3 \\
\hline $45-55$ & $\begin{array}{l}\text { Cold, less } \\
\text { comfortable }\end{array}$ & $\begin{array}{l}-600 \sim- \\
800\end{array}$ & $\begin{array}{l}\text { It's a little } \\
\text { cold }\end{array}$ & $\mathrm{c}$ & 5 \\
\hline $55-60$ & $\begin{array}{l}\text { Cool and } \\
\text { comfortable }\end{array}$ & $\begin{array}{c}-300 \sim- \\
600\end{array}$ & chilly breeze & $b$ & 7 \\
\hline $60-65$ & $\begin{array}{l}\text { Cool, very } \\
\text { comfortable }\end{array}$ & $\begin{array}{c}-200 \sim- \\
300\end{array}$ & $\begin{array}{l}\text { Comfortable } \\
\text { wind }\end{array}$ & A & 9 \\
\hline $65-70$ & $\begin{array}{l}\text { Warm and } \\
\text { comfortable }\end{array}$ & $-50 \sim-200$ & warm wind & B & 7 \\
\hline $70-75$ & $\begin{array}{l}\text { It's hot and } \\
\text { comfortable }\end{array}$ & $80 \sim-50$ & $\begin{array}{l}\text { The skin } \\
\text { feeling is not } \\
\text { clear, } \\
\text { showing the } \\
\text { wind }\end{array}$ & $\mathrm{C}$ & 5 \\
\hline $75-80$ & $\begin{array}{l}\text { It's stuffy and } \\
\text { uncomfortable }\end{array}$ & $160 \sim 80$ & $\begin{array}{l}\text { Hot air on } \\
\text { skin }\end{array}$ & $\mathrm{D}$ & 3 \\
\hline
\end{tabular}
Temperature and Humidity Index and Wind Efficiency Index 


\begin{tabular}{|c|c|c|c|c|c|}
\hline$>80$ & $\begin{array}{c}\text { Extremely hot } \\
\text { and } \\
\text { uncomfortable }\end{array}$ & $\geq 160$ & $\begin{array}{c}\text { Skin } \\
\text { discomfort }\end{array}$ & E & 1 \\
\hline
\end{tabular}

According to Ma Lijun's climate comfort evaluation model, the climate factor $\left(\mathrm{C}_{1}\right)$ evaluation model was established by expert scoring and analytic hierarchy process (AHP). The weight of temperature and humidity index (THI) and wind efficiency index (k) is given as follows[9]

$$
C_{1}=0.6 X_{T H I}+0.4 X_{k}
$$

In the formula, the values of temperature and humidity index (THI) and wind efficiency index (k) obtained according to formula (1) and (2) are calculated respectively. According to formula (3), $\mathrm{C}_{1}$ value is obtained, and with reference to evaluation criteria: $1<\mathrm{C}_{1} \leqslant 3$ represents "uncomfortable", $3<\mathrm{C}_{1}<5$ stands for "relatively uncomfortable", $5 \leqslant \mathrm{C}_{1}<7$ stands for "more comfortable", $7 \leqslant \mathrm{C}_{1} \leqslant 9$ stands for "comfort".

The final score of climate factor evaluation of Xining city is 8.2 , and the score of four cities is the highest, which is in the comfortable area. Guiyang, Changchun and Kunming scored 6.6, 5.8 and 7.8 respectively.

\section{2 comparison of industrial conditions}

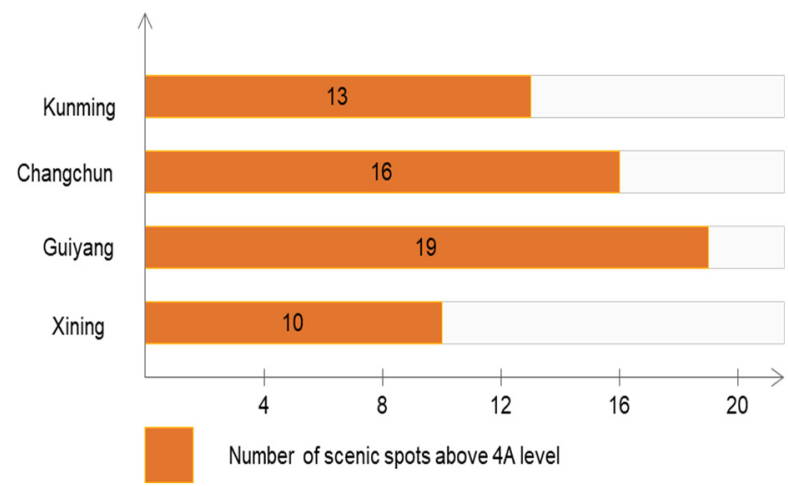

Figure 3-1 comparison of the number of $4 \mathrm{~A}+$ scenic spots in four summer resort cities

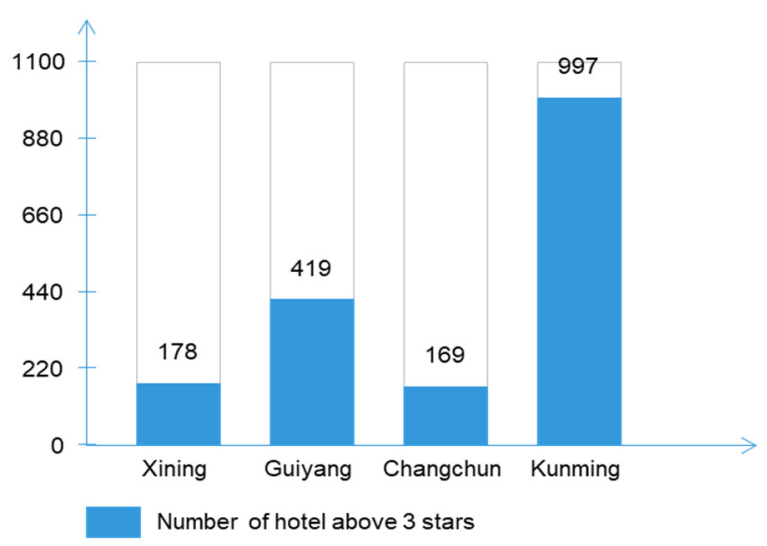

Figure 3-2 comparison of the number of hotels above 3 stars in four summer resort cities

Data source: Data collection of Ctrip platform
Table 3-4 tourism development status of four summer resort tourism cities in 2019

\begin{tabular}{llllc}
\hline region & Xining & Guiyang & Kunming & Changchun \\
\hline $\begin{array}{c}\text { Number } \\
\text { of tourists } \\
(10000)\end{array}$ & 2851.9 & 22934.2 & 18644.1 & 10156.5 \\
$\begin{array}{l}\text { Tourism } \\
\text { revenue } \\
(100\end{array}$ & 389.3 & 3098.0 & 2733.0 & 2191.4 \\
$\begin{array}{l}\text { million } \\
\text { yuan })\end{array}$ & & & & \\
\hline $\begin{array}{l}\text { Data source: Official Websites of culture and tourism bureaus of all } \\
\text { provinces and cities }\end{array}$
\end{tabular}

Figure 3-1 shows that among the four summer tourism cities, the number of $4 \mathrm{~A}+$ scenic spots in Xining is the least, lagging behind the other three cities. In Figure 3-2, the number of hotels above 3 stars in Xining city is also in a backward position among the four cities. The number of Hotels with more than 100 hotels is obviously different from Kunming, which is an obvious short board in Xining's summer tourism industry. The number of tourists and tourism income are important indicators to evaluate the development of tourism in a region, which can reflect the level of tourism industry in the region to a large extent. As the capital city of Xining, the number and income of tourism industry in Xining in 2019 is quite different from that of the other three cities, which is almost 9 times different.

\section{3 comparison of external environment}

\subsection{1 comparison of health care environment}

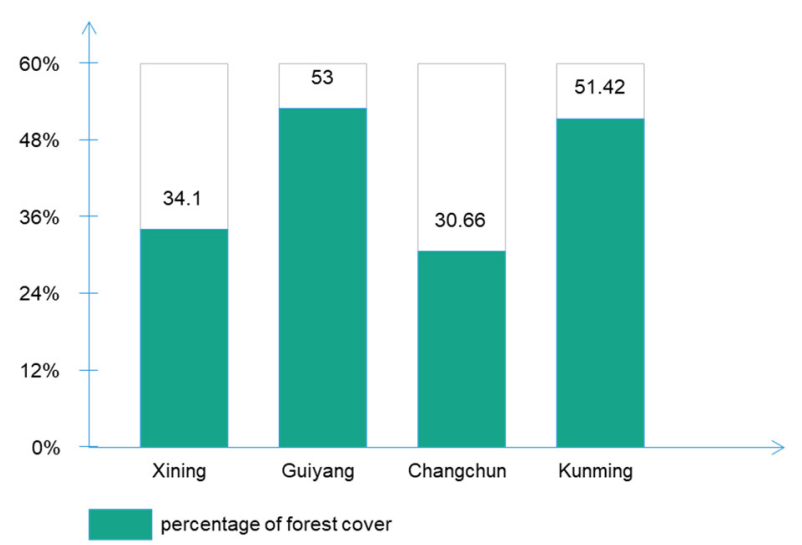

Figure 3-3 comparison chart of forest coverage rate of main summer resort cities

Data source: Ecological environment department and forest and grass Bureau of various provinces and cities

Table 3-5 air quality comparison of four summer resort cities in 2019

\begin{tabular}{|c|c|c|c|c|}
\hline city & Xining & Guiyang & Changchun & Kunming \\
\hline $\begin{array}{c}\text { Days of } \\
\text { good air }\end{array}$ & 351 & 357 & 330 & 361 \\
\hline $\begin{array}{c}\text { Proportion } \\
\text { in the } \\
\text { whole } \\
\text { year }\end{array}$ & $96.1 \%$ & $97.8 \%$ & $90.4 \%$ & $98.9 \%$ \\
\hline
\end{tabular}

Data source: Department of ecological environment of provinces and cities 
Forest coverage indirectly represents the green area of an area. It can not only purify the air, but also prevent wind and sand, maintain soil and water, and regulate the microclimate of a city, which is particularly important for a city. Among the four cities, Xining, which belongs to plateau continental climate, does not have a leading edge in forest coverage rate, and there is a certain gap with Guiyang and Kunming in Southwest China, but the forest coverage level of more than $30 \%$ has become an excellent livable city in China. The air quality of a city has a great impact on people's travel choice. People not only want to have a happy trip, but also to travel healthily. The air quality level of the four cities is generally high and even. The air quality of Xining city is also in the middle and upper level in the four cities. The fresh air is very attractive for summer vacation tourists and can meet the tourists' demand for high-quality air.

\subsection{2 comparison of cultural environment}

Table 3-6 number of cultural places in major summer resort cities in China

\begin{tabular}{|c|c|c|c|c|}
\hline city & Xining & Guiyang & Kunming & Changchun \\
\hline $\begin{array}{c}\text { Number } \\
\text { of } \\
\text { Museums }\end{array}$ & 17 & 35 & 103 & 48 \\
\hline $\begin{array}{c}\text { Art } \\
\text { gallery }\end{array}$ & 4 & 17 & 12 & 6 \\
\hline Library & 21 & 79 & 110 & 103 \\
\hline
\end{tabular}

Table 3-7 representative food culture streets in major summer resort cities in China

\begin{tabular}{|c|c|}
\hline region & Representative food culture district \\
\hline Xining & $\begin{array}{c}\text { Limeng pedestrian street, Wanda Plaza, Xinqian } \\
\text { international, Xinhualian Plaza, Wangfujing, } \\
\text { Mojia street, Shuijing lane }\end{array}$ \\
\hline Guiyang & $\begin{array}{c}\text { Xingli square, Grand Cross Square, Hengfeng } \\
\text { pedestrian street, dayingpo, future ark, } \\
\text { huaguoyuan Shopping Center }\end{array}$ \\
\hline Kunming & $\begin{array}{c}\text { Nanping pedestrian street, new snail Bay, Wanda } \\
\text { Plaza, Dadu skyscraper shopping center, Tongde } \\
\text { Kunming square, xiaoximen, Xiangyun street }\end{array}$ \\
\hline Changchun & $\begin{array}{c}\text { Chongqing Road Commercial Street, Dama } \\
\text { folk commercial street, Changjiang Road } \\
\text { Pedestrian Street, Guilin Road Commercial } \\
\text { Street, Shangri La style leisure Street, Panshi } \\
\text { Road Commercial Street, Hongqi Street }\end{array}$ \\
\hline Data source: Official Websites of provincial and municipal cultural and
\end{tabular}
tourism bureaus

Table 3-5 and table 3-6 show the number of cultural centers and representative food culture streets in four cities. It can be seen that the commercial food culture blocks in Xining are better constructed, but the number of more cultural museums and art galleries is significantly less than the other three cities, ranking the bottom.

\section{Advantages and disadvantages of summer tourism in Xining city}

\section{1 advantages of summer tourism in Xining}

\subsection{1 comfortable summer climate}

Climatic conditions are the most basic and important elements of summer tourism. Guiyang and Kunming are located in the southwest of China, and the rainy season is concentrated in summer, which leads to lower scores in these two cities. However, Changchun has too many sunny days in summer, and its high latitude makes its sunshine time too long, so its score is lower. Comparatively speaking, Xining is located in the northeast of QinghaiTibet Plateau, with a moderate altitude of 2,200 meters and an average temperature of $16.5^{\circ} \mathrm{C}$ in summer, which is suitable in temperature, humidity, sunshine and wind speed, and can better meet the summer needs of summer tourists. The climatic condition score of 8.2 above is ahead of the famous summer tourist cities. In addition, the whole tourist season is almost in summer, which has unique advantages in domestic summer tourist cities. The name of "Summer Capital" is worthy of the name.

\subsubsection{Good health environment}

Xining is located in Huangshui Valley, which is alluvial in the east of Qinghai-Tibet Plateau. There are many natural landscapes in the same area, such as snow-capped mountains and ice peaks, mountains and valleys, forests, wetlands, grasslands and so on, which are accompanied by abundant animal and plant resources. At present, it has formed an ecological city pattern of "the city is in the forest, cuddling in the tree, people in the green, forests and water depend on each other, and forests and roads are embedded". Its forest coverage rate of over $34.1 \%$ is at an excellent level in China, and it has been rated as a national excellent garden city for many times. High forest coverage rate and high-quality air environment provide conditions for Xining to develop "summer tourism+health care", extend and broaden the tourism industry chain, and also lay a foundation for Xining to create a bright spot for summer tourism development and enhance its differentiation from other summer cities.

\subsubsection{Unique and diverse cultural heritage}

Xining has a unique geographical position, which is located in the Hehuang Valley. As the intersection of ancient Chinese Yellow River civilization and Silk Road civilization, the only place where Tibetan Buddhist culture spread to Mongolia in the north, and the witness of many ethnic migrations in history, and the rise and fall of various northern regimes, the Qinghai-Tibet Plateau culture and Central Plains culture are integrated here, thus forming a unique cultural pattern with Central Plains farming culture as the main body and nomadic culture. At the same time, due to the gathering of many ethnic groups, there are Han culture, Islamic culture, Buddhist culture (Tibetan 
Buddhist culture) and a variety of folk religious cultures. These inherent unique and diverse cultures give more connotations to the development of summer tourism in Xining, and provide a guarantee for the healthy and sustainable development of summer tourism.

\subsection{Analysis of Disadvantages of Summer Tourism in Xining City}

\subsubsection{Infrastructure and supporting industries are backward}

Modern mass tourism is no longer limited to ordinary sightseeing, but pays more attention to the comfort and experience in the process of tourism. Related supporting services have become the biggest influencing factor to attract tourists. As a tourism mode that relies more on service effect, summer tourism has higher requirements on the quality of supporting industries such as hotels, restaurants, scenic spots and so on. The number of hotels above 3 stars determines the accommodation conditions of tourists. Some high-star hotels can also hold large-scale conferences, further extending the industrial chain of summer tourism, which is an important basis for building the industrial development model of "Summer+Exhibition". As a provincial capital city, Xining has too few $4 \mathrm{~A}+$ scenic spots and more than three-star hotels, which can not meet the service needs of tourists in food, accommodation and tourism, and even weakens the city tourism brand and lowers the tourism image of the whole city.

\subsubsection{The popularity is low and the number of tourists coming to Nanjing is small}

As far as the attraction of tourism resources is concerned, although Xining has a more pleasant summer climate and rich cultural and natural resources, when it comes to summer tourism cities, the first choice for most tourists is still Guiyang, Kunming and other classic summer cities, because these cities have formed a deep-rooted summer image in the hearts of the public, for example, "four seasons like spring" has become an exclusive adjective of Guiyang climate. However, people's cognition of Xining will still stagnate because of the impact on health caused by being located on the plateau. Although the slogan "Xining is the summer capital" has been mentioned and applied in recent years, due to the lack of effective publicity and the popularity of relevant general situation of Xining, there is still the current situation of low popularity of Xining as a summer tourist city. Tourists lack the intention to come to Nanjing, and the income of summer tourism in Xining is far from that in other popular cities.

\subsubsection{Low cultural atmosphere and excessive commercialization}

Although there are plenty of food culture blocks in Xining, the construction of these blocks generally lacks local characteristics and is over-commercialized. It pays attention to stimulating tourists' consumption and neglects cultural experience, which will lead to tourists' resistance, easily reduce the revisit rate, affect the reputation of tourism brands, and cause the loss of potential customers. In addition, the small number of cultural centers and museums is not conducive to the development of the integration of culture and tourism. Culture is the soul of tourism, representing the history and customs of a region. Tourists enjoy a cool climate while enjoying summer tourism, and they are more eager to be influenced by culture. If there are not enough cultural places as channels to convey local cultural values and ideas to tourists, the unique cultural atmosphere in the region will not be formed, which is not conducive to the sustainable development of summer tourism.

\section{Suggestions on the development of summer tourism in Xining}

\subsection{Extend the industrial chain and promote industrial integration and development}

Affected by terrain, geographical location, economic development level and other factors, Xining's supporting infrastructure, tourism products, the number of star-rated hotels and large-scale convention and exhibition centers in the tourism industry are not enough to meet tourists' choices and needs, which is far from other provincial capitals. It is necessary to increase investment in infrastructure construction, such as roads, transportation, water and electricity, public health, communications, etc., to improve the accessibility of Xining and the accessibility of traffic within the urban area, and to focus on building supporting industries such as hotels, bus lines and resorts. Secondly, the development level of many high-quality tourism resources in Xining is low at present, so the municipal government should deepen the openness, jointly develop with powerful enterprises, transfer the management right when necessary, stimulate the market vitality and create high-quality scenic spots; From the toplevel design, we should formulate policies to promote the development of summer tourism, so that summer tourism can be integrated with various industries.

\subsection{Highlight the climate advantage and launch the "Xiadu" brand}

At present, the influence of "Xiadu" brand in Xining has only spread to neighboring provinces, so it is urgent to open up domestic and international tourism markets. Xining municipal government needs to publicize the climate resources of Xining as the dominant factor of developing summer tourism in major cities in China, and also strengthen the association with tourism series routes, brands and other related aspects of neighboring provinces. At the same time, taking advantage of the pulling effect of online media on tourists' choice in the Internet era, the brand promotion is carried out through short videos and big $\mathrm{V}$ bloggers' recommendations, so as to improve the 
popularity and existence of Xining "Xiadu" brand in China and strive to become the first choice for tourists' summer tourism destinations.

\subsection{Excavate climate resources and create healthy features}

Xining not only enjoys good climatic conditions, but also has high forest coverage rate and good air quality, which are all necessary elements for the development of health care industry. "Summer tourism+health care" can fully realize the value of climate resources, and it is also a breakthrough for the integration and development of various industries in Xining. At present, the use of climate resources in various regions of China focuses on summer vacation. Xining should take the lead in firing the first shot, dig deep into the unique forest cultural connotation, rely on forest parks, nature reserves, forestry bases and wetland parks, give full play to the advantages of Xining's national forest city, introduce global advanced climate health technology and brands, develop climate health products, fully integrate the catering, accommodation and real estate industries of climate health summer tourism, build industrial clusters, and create characteristics for the whole country and even the whole world.

\subsection{Strengthen cultural empowerment and enhance the supply of characteristic tourism products}

Under the background of the integration of culture and tourism, the sustainable and healthy development of summer tourism can't be separated from the enrichment of culture. It is necessary to strengthen the idea of "strengthening the culture and promoting the culture by traveling". Integrating Xining's characteristic cultural resources and shaping a series of characteristic summer tourism products can create large-scale historical stage plays and enrich summer tourism activities according to the local traditional multi-ethnic culture. In addition, the local food culture of Xining, such as "Niangpi" and "Japonica skin", can also be integrated into summer tourism. What's more, keep up with the trend of "Smart Tourism", strengthen the modern elements and sense of science and technology of summer tourism, and focus on building industrial and agricultural science and technology museums, Expo parks, etc., and further enrich the types of tourism products.

\section{Conclusions}

Through comparative analysis, this paper summarizes the advantages and disadvantages of Xining compared with other domestic summer tourism destinations, and finds out the advantages of Xining's summer tourism in terms of climate and natural conditions, and the disadvantages of industrial and cultural environment. As a feasibility study of summer tourism destination in Xining, it can provide new ideas for the future development of tourism in Xining and further promotes to fill the gap of summer tourism destination in Northwest China.

\section{Author}

Author: Li Chen-Yang (2000-), female, from Puyang, Henan, Tourism Management undergraduate.

*Corresponding author: Chen Jin-lin (1981-), male, from Huzhu County, Qinghai Province, doctor, associate professor, research direction: regional tourism development and management, heritage tourism.

\section{Acknowledgments}

Supported by foundation of National Philosophy and Social Seciences Western Project (17XMZ077).

\section{References}

1. Ueneva: United Nations Intergovernmental Panel on Climate-Change, (2007). IPCC Fourth Assessment Report: Climate change 2007(AR4). https://doc.wendoc.com/b1f8d3c7fb09382af021fa08 9.html

2. Liu, Y.Y., Jin, Y.R. (2010) Overview of the development of summer tourism industry. Ecological Economy, 6: 115-118.

3. Chen, H., Yan, Y.C., Yue, S.P.(2015)The regional types and their temporal and spatial distribution characteristics of summer-relief climate in China. Progress in Geographical Sciences, 34(02): 175-184.

4. Yang, J., Zhang, Y.H., Xi, J.C.(2016)Study on the Comprehensive Evaluation of Suitability of China's Summer Resort Tourism Base. Resources Science, 38(12): 2210-2220.

5. Lu, W.L. (2019) There should be more cultural "enjoyment" in the coolness. China Travel News, 2019-09-03(003).

6. Chen, H.(2019)The "difficulties" and "breaks" of the upgrade of summer tourism. Contemporary Guizhou, 30: 68-69.

7. Yangguang.com.(2019).The 2019 China Changchun Summer Resort Tourism Industry Summit was held in Changchun, 40 cities were awarded the summer tourism city license. https//baijianhao.baidu.com,

8. W.T.Oliver, J.E.Wells.( 2016)Lysozyme as an alternative to growth promoting antibiotics in swine production. Journal of Animal Science and Biotechnology,7(01):34-40.

9. Ma, L.j., Sun,G.N.,Wang,J.J.(2009)Evaluation of the tourism climate comfort of the cities along the eastern coast of China. Progress in Geographical Sciences, 28(05):713-722. 